\title{
Ön Çapraz Bağ Lezyonlarının Otojen Hamstring Tendon Grefti Kullanılarak Anatomik Çift Band ve Tek Band Tekniği ile Rekonstrüksiyonu Sonrası Karşılaşırmalı Erken Dönem Klinik Sonuçlarımız
}

\author{
Burak Günaydın', Osman Tuğrul Eren², Raffi Armağan², Hasan Basri Sezer²
}

\begin{abstract}
ÖZET:
Ön çapraz bağ lezyonlarının otojen hamstring tendon grefti kullanılarak anatomik çift band ve tek band tekniği ile rekonstrüksiyonu sonrası karşılaştırmalı erken dönem klinik sonuçlarımız

Amaç: Bu çalışmanın amacı ön çapraz bağ yırtığı sonrasında anatomik çift band yöntemi ve anatomik tek band yöntemi kullanılarak ön çapraz bağ (ÖÇB) tamiri uygulanan hastaların ameliyat öncesi ve sonrası bulgularını karşılaştırmaktır.

Gereç ve Yöntem: Çalışmamızda 2007-2009 yılları arasında anatomik çift band yöntemiyle ÖÇB rekonstrüksiyonu ameliyatı uygulanan ve yeterli takibi olan 20 hasta ile, anatomik tek band yöntemiyle ÖçB rekonstrüksiyonu ameliyatı uygulanan ve yeterli takibi olan 20 hastanın sonuçları retrospektif olarak değerlendirildi. İi grubun Lysholm Skorlaması sonuçları, Modifiye Cincinnati Skorlaması sonuçları, IKDC skoru ve aktivite skalasına göre sonuçları, eklem hareket açıkığı sonuçları, stabilite test sonuçları, uyluk atrofisi sonuçları, tek bacakla uzun atlama testi sonuçları ve KT-1000 cihazı ile 15, 20, 30 pound kuvvetler uygulanarak yapıIan ölçüm sonuçları retrospektif olarak değerlendirildi. İki grubun karşılaştırmasında student $t$ testi, MannWhitney U testi, Anovo testi kullanılarak, p<0.05 değeri anlamlı kabul edildi.

Bulgular: Anatomik çift band tekniği kullanılan hastaların 20 (\%100)'si de erkek olup, yaş ortalaması 26.7 (18-35) yıl idi. Bu hastaların 14 (\%70)'ünün sağ, 6 (\%30)'sının sol dizine rekonstrüksiyon ameliyatı uygulandı. Anatomik tek band tekniği kullanılan hastaların ise 17 (\%85)'si erkek olup, yaş ortalama 26 (16-36) yıl idi. Tek band yöntemi kullanılan hastaların ise $11(\% 55)$ 'inin sağ, 9 (\%45)'unun sol dizine rekonstrüksiyon ameliyatı uygulandı. İki grubun ameliyat sonrası KT-1000 cihazı ile 20 pound ve 30 pound kuvvet uygulanarak yapılan ölçüm değerlerinde ise anatomik çift bant tekniğinin, tek band tekniğine göre anterior translasyonu daha anlamlı bir şekilde engellediğini saptandı $(p<0.05)$. Diğer ölçüm ve skorlamalarda ise istatistiksel anlamlı fark bulunmadı ( $p>0.05$ ).

Sonuç: Anatomik çift band ÖÇB rekonstrüksiyonunun, tek band ÖÇB rekonstrüksiyonuna göre 20 ve 30 poundluk kuvvetle yapılan KT 1000 ölçümlerinde anterior translasyonu daha anlamlı bir şekilde engellediği saptandı. Çift band ÖÇB rekonstrüksiyonun klinik sonuçlarını görüldüğünde, bu yöntemin kullanılmasının giderek artacağı kanısındayız.

Anahtar kelimeler: Ön çapraz bağ, artroskopi, rekonstrüktif cerrahi
\end{abstract}

\section{ABSTRACT:}

Early comparision results of anatomical single and double bundle anterior cruciate ligament reconstruction procedures by using autogenous hamstring tendon graft

Objective: Purpose of this study is to evaluate the results of anatomical single bundle and double bundle anterior cruciate ligament reconstruction procedures and compare the results between two groups.

Material and Methods: 20 patients had been treated by anatomical single bundle (group 1) and 20 patients were treated by anatomical double bundle technique (group 2) between 2007 and 2009. The patients'; Lysholm knee scores, Modified Cincinnati scores, knee stability tests, activity scales, examination results of knee range of motion, IKDC scores, thigh atrophy measurement results, one leg hop test scores and examination under 15, 20, 30 pound forces with KT-1000 machine were evaluated and compared between two groups retrospectively. Statistical analysis was performed by using student T test, Mann-Whitney U test and Anovo test, $\mathrm{p}<0.05$ was accepted as significant.

Results: For group 1; 17 (85\%) of the patients were male and $3(15 \%)$ of them were female, mean age was $26(16-36)$ years, $11(55 \%)$ of the lesions were on the right knee and $9(45 \%)$ of them were on the left knee. All of the patients in group 2 were male. For group 2; mean age was 26.7 years (18-35), 14 of the lesions (70\%) were on right knee and 6 of them were on the left knee (30\%). Anterior translation rates which had been tested by KT-1000 measurements with 20 and 30 pound forces were lesser for group 2 (statistically significant, p<0.05). There were no statistically significant difference for other comparisions.

Conclusion: Anterior translation after anatomical double bundle technique was statistically significantly lesser than anatomical single bundle technique when tested with KT-1000 machine under 20-30 pound forces. We believe in that; after evaluating more cases' clinical results which has been treated by anatomical double bundle anterior cruciate ligament reconstruction technique, more orthopaedic surgeon will prefer to use this technique.

Key words: Anterior cruciate ligament, arthroscopy, reconstructive surgery

Ş.E.E.A.H. Tıp Bülteni 2014;48(4):274-81 1izmir Tepecik Eğitim ve Araştırma Hastanesi, 1. Ortopedi ve Travmatoloji Kliniği, İmir-Türkiye 2istanbul Şişli Hamidiye Etfal Eğitim ve Araştırma Hastanesi, Ortopedi ve Travmatoloji Kliniği, İstanbul-Türkiye

Yazışma Adresi / Address reprint requests to: Burak Günaydın,

İzmir Tepecik Eğitim ve Araştırma Hastanesi, 1. Ortopedi ve Travmatoloji Kliniği, 4. Kat, Yenişehir, İzmir-Türkiye

E-posta / E-mail:

docburak@gmail.com

Geliş tarihi / Date of receipt: 6 Haziran 2014 / June 6, 2014

Kabul tarihi / Date of acceptance: 7 Ağustos 2014 / August 7, 2014 


\section{GíRiş}

Ön çapraz bağ yırtığı sık karşılaşılan ortopedik sorunlardan biri olup, dizde menisküslerden sonra en sık yaralanan yapıdır. Diz kinematiğindeki önemli görevleri nedeniyle yaralanmaları kalıcı ve ciddi fonksiyon bozukluklarına yol açabilir. Ön çapraz bağ yırtığının en sık rastlanan sebebi spor yaralanmalarıdır. Toplumumuzda artan spor aktivitelerine bağlı olarak yaralanma sıklığı giderek artmaktadır.

Ön çapraz bağ yırtı̆̆ının tedavisi konservatif veya cerrahi olarak yapılmaktadır. Tedavinin amacı hastayı en kısa sürede günlük ve sportif faaliyetlerine geri döndürmek, ayrıca dizi tekrarlayan travmalardan korumaktır. Her yeni travma, yeni bir meniskal, kondral ve bağ hasarına dolayısıyla daha instabil diz oluşturmaya zemin hazırlamaktadır (1). Yaralanmadan sonra geçen süre, aktivite düzeyi, yırtığın tipi, birlikte olan diğer diz patolojileri ve instabilite derecesi konservatif ve cerrahi tedavi arasında karar vermede belirleyici rol oynar. Hasta yaşı tedaviye karar vermede önemli bir faktör olmamakla birlikte, özellikle genç hastalarda fiziksel aktivitelerinin daha fazla olması nedeniyle erken dönemde cerrahi tedavi seçeneği önem kazanmaktadır (2-4). Ön çapraz bağ cerrahisinde amaç normal diz kinematiğini ve stabiliteyi sağlamak, dizin işlevsel kapasitesini arttırmak, diğer anatomik yapıları koruyarak yeni yaralanmaların önüne geçmek, yaralanma öncesindeki güç, hareket açıklığı ve işlevselliği yeniden kazandırmaktır (5). Artroskopik cerrahi teknikler ve rehabilitasyon prensiplerindeki gelişmelerle, ÖÇB yırtığının cerrahi tedavisi daha sık uygulanır hale gelmiştir.

\section{GEREÇ VE YÖNTEM}

Çalışmamızda 2007-2009 yılları arasında Şişli Etfal Eğitim ve Araştırma Hastanesi 1.Ortopedi ve Travmatoloji Kliniği'nde, anatomik çift band tekniği ve endobutton-CL yöntemi ile otojen hamstring tendonları kullanılarak artroskopik ÖÇB rekonstrüksiyonu uygulanan ve yeterli takibi olan 20 hasta ile, anatomik tek band tekniği ve endobutton-CL yöntemi ile otojen hamstring tendonları kullanılarak artroskopik
ÖÇB rekonstrüksiyonu uygulanan ve yeterli takibi olan 20 hastanın sonuçları retrospektif olarak değerlendirildi. Çalışmaya dahil edilen hastalardan bilgilendirilmiş onam formu alındı.

Hastaların ameliyat sonrası yapılan diz muayenesinde aktif ve pasif hareket açıklığı sonuçları, stabilite değerlendirmesi, uyluk atrofisini değerlendirmesi sonuçları karşılaştırıldı. Hastaların ameliyat sonrası stabilite için bakılan Lachman testi, ön-arka çekmece testi, pivot-shift testleri negatif, $1(+), 2(+)$ ve 3(+) olarak değerlendirildi $(6,7)$. Uyluk atrofisini değerlendirmede Risberg ve ark. uyguladıkları gibi, her iki uyluk çevresi patella üst sınırının $15 \mathrm{~cm}$ proksimalinden ölçülerek karşılaştırıldı (8).

Her iki grup hastaların bulgularını karşılaştırabilmek için, Uluslararası Diz Dökümantasyon komitesi standart diz bağ iyileşme formu (IKDC), IKDC aktivite skalası, Lysholm ve Modifiye Cincinati değerlendirme formları kullanıldı. Laksite ölçümü KT 1000 aparatı ile 15, 20 ve 30 pound kuvvet uygulanarak yapıldı. Fonksiyonel değerlendirme için tek bacak üzerinde sıçrama testi (one leg hop) uygulandı ve sağlam taraf ile karşılaştırıldı.

Veriler NCSS 2007 paket programında kaydedilmiş ve iki grubun karşılaştırmasında t testi, MannWhitney $U$ testi, Anovo testi kullanılarak $\mathrm{p}<0.05$ değeri anlamlı kabul edildi.

\section{BULGULAR}

Anatomik çift band tekniği kullanılan hastaların 20 (\%100)'si de erkek olup, yaş ortalaması 26.7 (1835) yıl idi. Bu hastaların 14 (\%70)'ünün sağ, 6 (\%30)'sının sol dizine rekonstrüksiyon ameliyatı uygulandı. Ön çapraz bağ kopma zamanı ile ameliyat arasında geçen süre ortalama 17 (1-48) aydı. Hastaların ortalama takip süresi 14.4 (5-38) ay; ameliyat sonrası spora tekrar başlama süresi ise ortalama 5.5 (3-12) aydı.

Anatomik tek band tekniği kullanılarak artroskopik ÖÇB rekonstrüksiyonu uygulanan hastaların ise 17 (\%85)'si erkek olup, yaş ortalama 26 (16-36) yıldı. Tek band yöntemi kullanılan hastaların 11 (\%55)'inin sağ, 9 (\%45)'unun ise sol dizine rekonstrüksiyon ameliyatı uygulandı. Ön çapraz bağ kopma zamanı ile ameliyat arasında geçen ortalama süre 19.2 (1-60) 
Tablo 1: Anatomik çift ve tek band tekniği ile artroskopik ÖÇB rekonstrüksiyonu uygulanan hastaların karşışşırmalı Lysholm skorlamasına göre sonuçları

\begin{tabular}{cccc}
\hline Lysholm skoru & Anatomik Çift Band & Anatomik Tek Band & Sonuç \\
\hline $95-100$ & 13 hasta & 14 hasta & Mükemmel \\
$84-94$ & 6 hasta & 6 hasta & Iyi \\
$65-83$ & 1 hasta & - & Orta \\
64 ve altı & - & - & Kötü
\end{tabular}

Tabıo 2: Anatomik çift ve tek band tekniği ile artroskopik öçB rekonstrüksiyonu uygulanan hastaların karşılaştırmalı Modifiye Cincinnati skorlamasına göre sonuçları

\begin{tabular}{cccc}
\hline Cincinnati Skoru & Anatomik Çift Band & Anatomik Tek Band & Sonuç \\
\hline $26-30$ & 20 hasta & 20 hasta & Mükemmel \\
$21-25$ & - & - & Iyi \\
$16-20$ & - & - & Orta \\
15 ve altı & - & Kötü
\end{tabular}

Tablo 3: Anatomik çift ve tek band tekniği ile artroskopik ÖÇB rekonstrüksiyonu uygulanan hastaların karşılaştırmalı IKDC skorlamasına göre sayı ve oranları

\begin{tabular}{lcc}
\hline IKDC Skoru & Anatomik Çift Band & Anatomik Tek Band \\
\hline A (Normal) & $\mathrm{n}: 12(\% 60)$ & $\mathrm{n}: 12(\% 60$ \\
B (Normale yakın) & $\mathrm{n}: 7(\% 35)$ & $\mathrm{n}: 8(\% 40)$ \\
C (Anormal) & $\mathrm{n}: 1(\% 5)$ & - \\
D (Kötü) & - & - \\
\hline
\end{tabular}

n: hasta sayısı

aydı. Hastaların ortalama takip süresi 13.5 (5-22) ay; spora tekrar başlama süreleri ise 5.2 (3-10) aydı.

Anatomik çift band tekniği ile artroskopik ÖÇB rekonstrüksiyonu uygulanan hastaların Lysholm skoru ortalaması 94.3 (83-100) iken; tek band tekniği uygulanan hastalarda 95.6 (85-100) olarak bulundu (Tablo1).

Modifiye Cincinnati skoru ortalaması, anatomik çift band tekniği ve anatomik tek band tekniği uygulanan hastalarda, sırasıyla, 29.2 (27-30) ve 29.5 (2630) olarak bulunmuş olup, hastaların \%100'ü mükemmel olan grupta yer almıştır (Tablo 2).

Anatomik çift band tekniği uygulanan hastaların son kontrollerinde IKDC skorlamasında, 19 (\%95) hasta A ve B skor alan grupta olup, kötü sonuç alan hastamız bulunmamaktaydı (Tablo 3). IKDC skoru C olan hastada ise travmanın spor kazası dışındaki nedenlerle oluştuğu görüldü. Anatomik tek band tekniği uygulanan hastaların son kontrollerinde IKDC skorlamasında, tüm hastalar A ve B skor alan grupta olup, anormal ve kötü sonuç alan hasta yoktu (Tablo $3)$.

Anatomik çift band tekniği ile artroskopik ÖÇB rekonstrüksiyonu uygulanan hastaların travma öncesi, ameliyat öncesi ve son kontrolleri sırasındaki aktivite durumları IKDC aktivite skalasına göre değerlendirildi. Travma öncesi seviye I ve II'de 20 (\%100) hasta bulunurken, ameliyat öncesinde 3 (\%15) hasta, son kontroller sırasında ise 14 (\%70) hasta bulunmaktaydı. Ameliyat öncesi seviye IV grubunda 9 (\%45) hasta yer alırken son kontroller sırasında sadece bir (\%5) hastanın bu grupta yer aldığı tespit edildi (Tablo 4).

Anatomik tek band tekniği uygulanan hastaların travma öncesi, ameliyat öncesi ve son kontrollerindeki IKDC aktivite skalasına göre aktivite durumları değerlendirildiğinde; travma öncesi seviye I ve II'de 19 (\%95) hasta bulunurken, ameliyat öncesinde 2 (\%10) hasta, son kontroller sırasında ise 16 (\%80) hasta bulunmaktaydı. Ameliyat öncesi seviye IV grubunda 9 (\%45) hasta yer alırken son kontroller sırasında hiçbir hastanın bu grupta yer almadığı tespit edildi (Tablo 5).

Ortalama fleksiyon derecesi anatomik çift band tekniği ile artroskopik ÖÇB rekonstrüksiyonu uygulanan hastalarda $133^{\circ}\left(120^{\circ}-140^{\circ}\right)$ olarak bulundu. Ortalama fleksiyon derecesi anatomik tek band tekniği ile artroskopik ÖÇB rekonstrüksiyonu uygulanan 
Tablo 4: Anatomik çift band tekniği ile artroskopik ÖÇB rekonstrüksiyonu uygulanan hastaların IKDC aktivite skalasına göre üç zamanlı oranları

\begin{tabular}{lccc}
\hline Aktivite Seviyesi & Travma Öncesi & Ameliyat öncesi & Son muayene \\
\hline Seviye 1 (Yoğun) & $\mathrm{n}: 18(\% 90)$ & - & $\mathrm{n}: 8(\% 40)$ \\
Seviye 2 (Orta) & $\mathrm{n}: 2(\% 10)$ & $\mathrm{n}: 3(\% 15)$ & $\mathrm{n}: 6(\% 30)$ \\
Seviye 3 (Düşük) & - & $\mathrm{n}: 8(\% 40)$ & $\mathrm{n}: 5(\% 25)$ \\
Seviye 4 (Sedanter) & - & $\mathrm{n}: 9(\% 45)$ & $\mathrm{n}: 1(\% 5)$ \\
\hline
\end{tabular}

n: hasta sayısı

Tablo 5: Anatomik tek band tekniği ile artroskopik ÖçB rekonstrüksiyonu uygulanan hastaların IKDC aktivite skalasına göre üç zamanlı oranları

\begin{tabular}{lccc}
\hline Aktivite Seviyesi & Travma Öncesi & Ameliyat öncesi & Son muayene \\
\hline Seviye 1 (Yoğun) & $\mathrm{n}: 17(\% 85)$ & - & $\mathrm{n}: 11(\% 55)$ \\
Seviye 2 (Orta) & $\mathrm{n}: 2(\% 10)$ & $\mathrm{n}: 2(\% 10)$ & $\mathrm{n}: 5(\% 25)$ \\
Seviye 3 (Düşük) & $\mathrm{n}: 1(\% 5)$ & $\mathrm{n}: 9(\% 45)$ & $\mathrm{n}: 4(\% 20)$ \\
Seviye 4 (Sedanter) & - & $\mathrm{n}: 9(\% 45)$ & - \\
\hline
\end{tabular}

$\mathrm{n}$ : hasta sayısı

Tablo 6: Anatomik çift band tekniği ile artroskopik ÖçB rekonstrüksiyonu uygulanan hastaların öçB stabilite test sonuçları

\begin{tabular}{|c|c|c|c|c|}
\hline Stabilite testi & (-) Negatif & (+) Pozitif & (++) Pozitif & (+++) Pozitif \\
\hline Pivot-Shift & n:17 (\%85) & $\mathrm{n}: 3(\% 15)$ & $\mathrm{n}: 0$ & $\mathrm{n}: 0$ \\
\hline Ön Çekmece & n:4 (\%20) & $\mathrm{n}: 15$ (\%75) & n:1 (\%5) & $\mathrm{n}: 0$ \\
\hline Pasif Lachman & n:12 (\%60) & n:7 (\%35) & $\mathrm{n}: 1(\% 5)$ & $\mathrm{n}: 0$ \\
\hline $\begin{array}{l}\text { Son Nokta Hissi } \\
\text { (Sert/Yumuşak) }\end{array}$ & \multicolumn{2}{|c|}{$\begin{array}{c}\text { Sert } \\
20(\% 100)\end{array}$} & \multicolumn{2}{|c|}{ Yumuşak } \\
\hline
\end{tabular}

Tablo 7: Anatomik tek band tekniği ile artroskopik ÖÇB rekonstrüksiyonu uygulanan hastaların ÖÇB stabilite test sonuçları

\begin{tabular}{lcccc}
\hline Stabilite testi & (-) Negatif & (+) Pozitif & (++) Pozitif & (+++) Pozitif \\
\hline Pivot-Shift & $\mathrm{n}: 12(\% 60$ & $\mathrm{n}: 8(\% 40)$ & $\mathrm{n}: 0$ & $\mathrm{n}: 0$ \\
Ön Çekmece & $\mathrm{n}: 4(\% 20)$ & $\mathrm{n}: 16(\% 80)$ & $\mathrm{n}: 0$ & $\mathrm{n}: 0$ \\
Pasif Lachman & $\mathrm{n}: 7(\% 35)$ & $\mathrm{n}: 11(\% 55)$ & $\mathrm{n}: 2(\% 10)$ & Yumuşak \\
Son Nokta Hissi & & Sert & & - \\
(Sert/Yumuşak) & 20 (\%100) & & \\
\hline n: hasta sayısı & & &
\end{tabular}

hastalarda $136^{\circ}\left(125^{\circ}-140^{\circ}\right)$ olarak bulundu.

Son kontrolleri sırasında hastalara pasif Lachman, pivot-shift, son nokta hissi ve ön çekmece testleri uygulandı. Sonuçlar Amerikan Tıp Birliği tarafından önerildiği şekilde; 0-2mm:(-), 3-5mm:(+), 6-10 $\mathrm{mm}:(++), 11-15 \mathrm{~mm}:(+++)$ olarak değerlendirildi (Tablo 6-7) (7). Hastalarımızın hiçbirinde $10 \mathrm{~mm}$ üzerinde deplasman tespit edilmedi.
Uyluk atrofisini değerlendirmede patella üst sınırından $15 \mathrm{~cm}$ proksimalinden her iki uyluk çevreleri ölçülerek karşılaştırıldı, tespit edilen uzunluk farklarına göre üç dereceye ayrıldı (9). Anatomik çift band tekniği ile artroskopik ÖÇB rekonstrüksiyonu uygulanan hastaların ortalama atrofi değeri $18 \mathrm{~mm}$ (dağılım $0 \backslash 40 \mathrm{~mm}$ ) olarak bulundu (Tablo 8). Anatomik tek band tekniği ile artroskopik ÖÇB rekonstrüksiyonu 
Tablo 8: Anatomik çift ve tek band tekniği ile artroskopik ÖÇB rekonstrüksiyonu uygulanan hastaların karşıllaştırmalı olarak her iki uyluk çevreleri arasındaki fark oranları

\begin{tabular}{llc}
\hline $\begin{array}{l}\text { Uyluk Çevre } \\
\text { Farkı }\end{array}$ & $\begin{array}{l}\text { Anatomik } \\
\text { Çift Band }\end{array}$ & $\begin{array}{l}\text { Anatomik } \\
\text { Tek Band }\end{array}$ \\
\hline$<10 \mathrm{~mm}$ & $\mathrm{n}: 8(\% 40)$ & $\mathrm{n}: 12(\% 60)$ \\
$10-20 \mathrm{~mm}$ & $\mathrm{n}: 7(\% 35)$ & $\mathrm{n}: 6(\% 30)$ \\
$>20 \mathrm{~mm}$ & $\mathrm{n}: 5(\% 25)$ & $\mathrm{n}: 2(\% 10)$ \\
\hline n: hasta sayısı & &
\end{tabular}

Tablo 9: Anatomik çift ve tek band tekniği ile artroskopik ÖÇB rekonstrüksiyonu uygulanan hastaların karşılaştırmalı olarak tek bacakla uzun atlama test yüzdeleri

\begin{tabular}{lcc}
\hline Atlama yüzdesi & $\begin{array}{c}\text { Anatomik } \\
\text { Çift Band }\end{array}$ & $\begin{array}{c}\text { Anatomik } \\
\text { Tek Band }\end{array}$ \\
\hline$\% 95$ 'den fazla & $\mathrm{n}: 7(\% 35)$ & $\mathrm{n}: 11(\% 55)$ \\
$\% 85-95$ arasında & $\mathrm{n}: 9(\% 45)$ & $\mathrm{n}: 5(\% 25)$ \\
$\% 75-85$ arasında & $\mathrm{n}: 3(\% 15)$ & $\mathrm{n}: 3(\% 15)$ \\
$\% 75$ 'den az & $\mathrm{n}: 1(\% 5)$ & $\mathrm{n}: 1(\% 5)$ \\
\hline n: hasta sayısı & &
\end{tabular}

Tablo 10: Anatomik çift ve tek band tekniği ile artroskopik ÖÇB rekonstrüksiyonu uygulanan hastaların karşılaştırmalı ortalama kantitatif bağ laksite ölçümü (translasyon) değerlendirilmesi

\begin{tabular}{lcc}
\hline Translasyon & $\begin{array}{c}\text { Anatomik } \\
\text { Çift Band }\end{array}$ & $\begin{array}{c}\text { Anatomik } \\
\text { Tek Band }\end{array}$ \\
\hline$\leq 2 \mathrm{~mm}$ & $\mathrm{n}: 17(\% 85)$ & $\mathrm{n}: 11(\% 55)$ \\
$3-5 \mathrm{~mm}$ & $\mathrm{n}: 3(\% 15)$ & $\mathrm{n}: 9(\% 45)$ \\
$6-10 \mathrm{~mm}$ & - & - \\
$>10 \mathrm{~mm}$ & - & - \\
\hline
\end{tabular}

n: hasta sayısı

uygulanan hastaların ortalama atrofi değeri $9 \mathrm{~mm}$ (dağılım: -5 \40 mm) olarak bulundu. Bir hastada ameliyat olan ekstremitedeki çevre uzunluğu ameliyat olmayan taraftan daha fazla olarak ölçüldü (Tablo 8). Hastalardan tek ayağı üzerinde zıplayabildiği kadar ileriye atlaması istendi ve her iki diz için üçer kez tekrarlanan test sonrası ameliyat olan ve olmayan taraftaki ölçüm sonuçları karşılaştırıldı $(10,11)$. Tek band veya çift band uygulanan her iki gruptan 16 $(\% 80)^{\prime}$ şar hastada \%85' in üzerinde değerlere ulaşıldı (Tablo 9).

Son kontrolde KT-1000 cihazı ile 15, 20, 30 pound'luk kuvvet uygulanarak yapılan ölçümlerde, translasyonun karşı sağlam diz ile karşılaştırılmasından ortaya çıkan sonuçlar iki grup arasında eş kuvvet değerleri için karşılaştırılmış olup Tablo 10'de özetlenmiştir.

Anatomik çift band tekniği ile artroskopik ÖÇB rekonstrüksiyonu uygulanan hastaların 15 pound kuvvet için ortalama laksite $1.15 \mathrm{~mm}$; 20 pound kuvvet için ortalama laksite $1.075 \mathrm{~mm} ; 30$ pound kuvvet için ortalama laksite $1.075 \mathrm{~mm}$ saptandı (Tablo 10).

Anatomik tek band tekniği ile artroskopik ÖÇB rekonstrüksiyonu uygulanan hastaların 15 pound kuvvet için ortalama laksite $2.025 \mathrm{~mm} ; 20$ pound kuvvet için ortalama laksite $2.4 \mathrm{~mm} ; 30$ pound kuvvet için ortalama laksite $1.9 \mathrm{~mm}$ saptandı (Tablo 10).

Yapılan analiz sonucunda iki grubun yapılan Lysholm Skorlaması sonuçları, Modifiye Cincinnati Skorlaması sonuçları, IKDC skoru ve aktivite skalasına göre sonuçları, eklem hareket açıkığı sonuçları, stabilite test sonuçları, uyluk atrofisi sonuçları, tek bacakla uzun atlama testi sonuçları ve KT-1000 cihazı kullanılarak 15 pound kuvvet uygulanarak yapılan ölçüm değerleri arasında anlamlı fark saptanmadı ( $p>0.05$ ). KT-1000 cihazı ile yapılan ölçümlerde 20 pound ve 30 pound kuvvet uygulanarak yapılan ölçüm değerlerinde ise anatomik çift bant tekniğinin, tek band tekniğine göre anterior translasyonu daha anlamlı bir şekilde engellediğini saptandı $(p<0.05)$.

\section{TARTIŞMA}

Tüm dünyada sporla ilgilenen kişi sayısı artmakta olup; çok sayıda spor yaralanması meydana gelmektedir. Bu yaralanmalarda diz, en sık yaralanan eklem olarak karşımıza çıkmaktadır. Dizde en sık görülen bağ yaralanması ön çapraz bağ yaralanmasıdır. Genel popülasyonda görülme sıklığı yaklaşık 1/3000'dir (12,13).

ÖÇB yaralanmaları sonucunda, bireyin aktivitesi kısıtlanmakta, yaşam kalitesi düşmekte ve diz ekleminde meydana gelebilecek yaralanmaların sayısı artmaktadır. Dizi bu tür komplikasyonlardan korumak ve kişiyi daha kaliteli bir yaşam standardına ulaştırabilmek için, uygun bireylerde yaralanmış olan ÖÇB'ın tedavisi gerekmektedir. ÖÇB cerrahisinde, özellikle son 20 yılda artroskopik tekniklerin ilerlemesi ile önemli gelişmeler kaydedilmiştir (14). Yapılan çalış- 
malar sonucunda ÖÇB'ın biyolojisi, biyomekaniği, patolojisi daha iyi anlaşılmasına rağmen ÖÇB tedavisinde bir standart oluşturulamamıştır.

ÖÇB yaralanmalarında hangi tedavi metodu seçilirse seçilsin temel amaç; dizi tekrarlayan travmalardan korumak, hastayı mümkün olduğunca kısa sürede yaralanma öncesi aktivitesine ve rutin işlerine geri döndürmek olmalıdır (5).

Anatomik ÖÇB çift band rekonstrüksiyon tekniğinin ana potansiyel avantajı diz ekleminin rotasyonel stabilitesinin geri gelmesini sağlamasıdır. ÖÇB rekonstrüksiyonlarının çoğu izometrik tek band tekniği ile yapılmaktadır. Tek band yöntemi ile yapılan ÖÇB rekonstrüksiyonu sadece anteromedial band görevi görür. Anteromedial band tüm eklem hareketlerinde gergin olmasına rağmen en gergin olduğu pozisyon fleksiyondur. Anteromedial band fleksiyondaki dizin anterior translasyonunu engelleyen en önemli yapıdır. Bu ekstansiyonda normal diz laksitesini ve kinematiğini restore etmez (15). Diz kinematiğini düzeltmek için günümüzde çift band anatomik ÖÇB rekonstrüksiyonu yapılmaktadır (15).

Robotlarla yapılan simülasyon çalışmalarında çift band yöntemi ile rekonstrüksiyonun ÖÇB'nin anatomik yapısına biyomekanik olarak daha fazla uyacağı ve çift band ÖÇB rekonstrüksiyonlarında anteromedial ve posteromedial bandlara binen yükün diz ekleminin farklı fleksiyon derecelerinde değiştiği gösterilmiştir (16). Aynı çalışmada, tek ve çift band ÖÇB rekonstrüksiyonları karşılaştırıldığında, çift band tekniğinde diz ekleminin anteroposterior stabilitesinin daha iyi olduğu vurgulanmıştır (16). Bu bulgular çift band tekniğinin tek band tekniğine göre biyomekanik olarak daha avantajlı olduğunu göstermektedir.

Rekonstrükte edilen posterolateral band, izometrik yerleştirilen greftin koptuğu açılarda stabiliteyi restore etmektedir (17). Ayrıca $150^{\circ}$ fleksiyonda anterior kaymayı ve Pivot shifti engellediği gösterilmiştir. Bu nedenle birçok yazar her türlü diz hareketinde normale yakın ÖÇB fonksiyonunun çift band tekniği ile sağlanabildiğini bildirmişlerdir. Tek band yöntemi ile yapılan ÖÇB rekonstrüksiyonunun yeterli rotasyonel stabilite sağlamadığı bildirilmiştir. Çift band tekniği hamstring tendonuyla uygulanabilmektedir. Quadriseps tendonu da çift banda uygun şekilde hazırlanıp, çift tibial tünelden uygulanabilmektedir
(18). Hamstring tendon greftinde potansiyel elongasyon ameliyat sonrası dönemde ortaya çıkabilmektedir; ayrıca greft fiksasyonu daha az güvenilir, greftkemik iyileşmesi daha fazla zamana ihtiyaç duyabilmekte ve tünelde potansiyel bir genişleme olabilmektedir (19).

KT-1000 cihazı ile diz ekleminde yapılan ölçümler tibianın ön-arka planda femura göre öne yer değiştirmesini, bir başka deyişle diz ekleminin laksisitesini ortaya koymaya yönelik objektif ölçümlerdir. Yapılan çalışmalar KT-1000 cihazı ile güvenilir bir şekilde diz eklemi laksisitesinin belirlenebildiğini ve bu cihazın klinik kullanımının başarılı olduğunu göstermiştir $(20,21)$.

108 hastalı prospektif randomize bir çalışmada, Adachi ve arkadaşları anatomik çift band ÖÇB rekonstrüksiyon ile tek band ÖÇB rekonstrüksiyon tekniğini, ortalama takip süresi 32 ay olan, hasta grubunda karşılaştırmıştır. Fonksiyonel diz skorlamaları ve KT-2000 kullanılarak anteroposterior diz stabilitesini ölçümleri yapılmıştır. Çalışma sonucunda her iki grup arasında fonksiyonel ve stabilite açısından bir fark saptanmamıştır (22).

Yapılan bu klinik çalışmaların sonuçları göz önüne alındığında, anteroposterior diz stabilitesinin değerlendirilmesi üzerinde yoğunlaşılmıştır. Bununla birlikte, anatomik çift band ÖÇB rekonstrüksiyonunun en önemli potansiyel avantajı, bu tekniğin daha iyi diz eklem rotasyonel stabilitesi sağlayabilir olmasıdır. Bu nedenle, ÖÇB tek band rekonstrüksiyon ile anatomik çift band ÖÇB rekonstrüksiyonunu karşıIaştıran karmaşık çalışma sonuçları üç boyutlu in vivo diz kinematiğinin değerlendirmesini içermelidir. Literatürde 3 boyutlu diz kinematiğini ölçmek için farklı potansiyel yaklaşımlar önerilmektedir. Bunlar yumuşak doku ağırıkkı MRI, yüksek hızlı stereo-radyografi, fluroskopi, ve MRI tabanlı bilgisayar modelleri gibi video hareketi analizi ve elektromanyetik izleme aletini içermektedir (23). Bu teknikler in vivo diz kinematiğinin doğru ölçülmesine ve ÖÇB rekonstrüksiyonundan sonra gelecekte in vivo rotasyonel diz stabilitesinin değerlendirilmesine izin verirler. Bununla birlikte, diz ekleminin rotasyonel stabilitesinin ölçülmesi için klinik ortamda standart ölçüm yöntemleri ve diz ekleminin in vivo kinematiğinin tespit edilmesi için, bu alanda yapılacak araştırmala- 
ra ihtiyaç duyulmaktadır.

Klinik çalışmalar, ÖÇB rekonstrüksiyonundan sonra uzun dönemli fonksiyonel sonuçların gelişim aşamasında olduğunu göstermektedir $(24,25)$. Literatürde anatomik olarak ÖÇB'nin iki fonksiyonel bağ içerdiği (AM ve PL band) en güzel şekilde gösterilmiştir.

Kadavra çalışmaları her iki fonksiyonel ÖÇB bandın rekonstrüksiyonunun konvansiyonel ÖÇB tek bağ rekonstrüksiyonundan daha normale yakın bir diz kinematiğini sağlayabileceğini ve diz ekleminin rotasyonel kinematiğinin daha iyi olabileceğini göstermiştir. AM ve PL bağın her ikisi içinde cerrahi rekonstrüksiyonun anatomik ve biyomekanik olarak yapılması gerektiğine inanıyoruz (26). Buna ek olarak, Tashman ve arkadaşları, tarafından yapılan in vivo çalışmalarda, ÖÇB tek bağ rekonstrüksiyonunun anteroposterior diz stabilitesini geri kazandırdığını ancak diz ekleminin rotasyonel stabilitesini geri kazandırmadı̆̆ını göstermiştir (27).

Bu çalışmanın sonucunda daha öncede yayınlanmış çalışmalar gibi çift band ÖÇB rekonstrüksiyonun, tek band ÖÇB rekonstrüksiyonuna göre rotasyonel ve anterior translasyonel stabilite kontrolünü daha iyi sağladığını, komplikasyonu azalttığını, ameliyat sonrası düzelme üzerine etkili olduğu gördük. Dikkate alınacak bir nokta olarak, ameliyat süresi ve ameliyat maliyetinin yükseleceği ve daha ileri bir cerrahi teknik beceriye gereksinim olmasına rağmen, çift band ÖÇB rekonstrüksiyonun klinik sonuçlarını görüldügünde, bu yöntemin kullanılmasının giderek artacağı kanısındayız.

\section{KAYNAKLAR}

1. Altınel E. Özdemir H. ÖÇB yaralanmalarında doğal seyir. Acta Orthop Trauma Turc 1999; 33-5; 381-4.

2. Barber FA, Elrod BF, MC Guire DA, Paulos LE. Is an anterior cruciate ligament reconstruction out come age dependent? Arthroscopy 1996; 12: 720-5.

3. Sloane PA, Brazier H, Murphy AW, Collins T. Evidence based medicine in clinical practice: how to advise patients on the influence of age on the outcome of surgical anterior cruciate ligament reconstruction: a review of the literature. $\mathrm{Br} J$ Sports Med 2002; 36: 200-3.

4. Dunn WR, Lyman S, Lincoln AE, Amoroso PJ, Wickiewicz T, Marx RG. The effect of anterior cruciate ligament reconstruction on the risk of knee reinjury. Am J Sports Med 2004; 32: 1906-14.

5. Aydın AT. Ön çapraz bağ yaralanmasının tedavisinde endikasyonlar. Acta Orthop Travmatol Turc 1999; 33: 385-8.

6. Jain DK, Amaravati R, Sharma G. Evaluation of the clinical signs of anterior cruciate ligament and menisca linjuries. Indian J Orthop 2009; 43: 375-8.

7. Hughston JC, Andrews JR, Cross MJ, Moschi A. Classification of knee ligament instabilities. Part I. The medial compartment and cruciate ligaments. J Bone Joint Surg Am 1976; 58: 159-72.

8. May Arna Risberg, Arne Ekeland. Assesment of functional tests after anterior cruciate ligament surgery. Journal of Orthopaedic \& Sports Physical Therapy 1994; 19: 212-7."

9. Barber SD, Noyes FR, Mangine RE, McCloskey JW, Hartman W. Quantitative Assesment of functional limitations in normal and anterior cruciate ligament deficient knees. Clinical Orthopaedics and Related Research 1990; 255: 204-14.

10. Reznik A, Sachs RA, Daniel DM, Stone ML. Complications of The Knee Ligament Surgery in Knee Ligaments Structure, Function, Injury and Repair. NewYork 1990.p. 505-20.

11. Sach R, Daniel DM, Stone ML, Garfein RF. Patellofemoral Problems After Anterior Cruciate Ligament Reconstruction, Am J Sports Med 1989; 17: 760-5.

12. Gordon MD, Steiner ME. Anterior Cruciate Ligament Injuries. Orthopaedics Knowledge Update; Sports Medicine; 2004; 3; 169-81.

13. Woo SL, Knaub MA, Apreleva M. Biomechanics of Ligament in sports Medicine; Sports Injuries: Mechanisms, Prevention \& Treatment, $2^{\text {nd }}$ Edition. 2001; Chapter. p. 77-85.

14. Noyes FR, Magine RE. EarlyKnee Motion After Open and Arthroscopic Anterior Cruciate Ligament Reconstruction. Am J Sports Med. 1987; 15: 149-55.

15. Luites JW, Wymenga A, Blankevoort L, Kooloos JM. Description of the Attachments Geometry of the Anteromedial and Posterolateral Bundles of the ACL from Arthroscopic Perspective for Anatomic Tunnel Placement. Knee Surgery Sports Traumatol Arthroscopy 2007; 15: 1422-31.

16. Anna E Fox, David S Johnson. Anterior Cruciate Ligament Reconstruction: Bone-Patellar Tendon-Bone Compared with Double Semitendinosus and Gracilis Tendon Grafts. J. Bone Joint Surg Am 2005; 87: 1882-3.

17. Steiner ME, Brown C, Zarins B, Brownstein B, Koval PS, Stone $P$. Measurement of anterior-posterior displacement of the knee: A comparison of the results with instrumented devices and with clinical examination. J Bone Joint Surg 1990; 72: 1307-15.

18. Pederzini L, Adriani E, Botticella C, Tossi M. Double Tibial Tunnel Quadriceps Tendon in Anterior Cruciate Ligament Reconstruction. Arthroscopy 2000; 16: E9.

19. Chen C, Chuang T, Wang K, Chen W, Shih C. Arthroscopic $A C L$ reconstruction with quadriceps tendon autograft: clinical outcome in 4-7 years. Knee Surg Sports Traumatol Arthrosc 2006; 14: 1077-85.

20. Bach BR, Warren RF, Flyn WM, Kroll M, Wickiewiecz TL. Arthrometric evaluation of knee that have a torn anterior cruciate ligament. J Bone Joint Surg Am 1990; 72: 1299-306.

21. Daniel DM, Stone ML, Sachs $R$, Malcolm L. Instrumented measurement of anterior knee laxity in patients with acute anterior cruciate ligament disruption. Am J Sports Med 1985; 13 : 401-7.

22. Adachi $N$, Ochi $M$, Uchio $Y$, Iwasa J, Kuriwaka $M$, Ito $Y$. Reconstruction of the anterior cruciate ligament. Single- versus double-bundle multistranded hamstring tendons. J Bone Joint Surg $\operatorname{Br} 2004 ; 86: 515-20$. 
23. Steckel H, Vadala G, Davis D, Fu FH. 2D and 3D 3-tesla magnetic resonance imaging of the double bundle structure in anterior cruciate ligament anatomy. Knee Surg Sports Traumatol Arthrosc 2006; 14: 1151-8.

24. Daniel DM, Stone ML, Dobson BE, Fithian DC, Rossman DJ, Kaufman KR. Fate of the ACL-injured patient. A prospective outcome study. Am J Sports Med. 1994; 22: 632-44.

25. Fithian DC, Paxton EW, Stone ML, Luetzow WF, Csintalan RP, Phelan D, et al. Prospective trial of a treatment algorithm for the management of the anterior cruciate ligament-injured knee. Am J Sports Med 2005; 33: 335-46.
26. Schutte MJ, Dabezies EJ, Zimny ML, Happel LT. Neural anatomy of the human anterior cruciate ligament. J Bone Joint Surg Am. 1987; 69: 243-7.

27. Tashman S, Collon D, Anderson K, Kolowich P, Anderst W. Abnormal rotational knee motion during running after anterior cruciate ligament reconstruction. Am J Sports Med 2004; 32: 975-83. 